\title{
Focal cerebral hypoperfusion and selective cognitive deficit in dementia of the Alzheimer type
}

\author{
PIERRE CELSIS, ALAIN AGNiEL, MICHÈle PUEL, ANDRÉ RASCOL, \\ JEAN-PIERRE MARC-VERGNES \\ From LHEC-INSERM U 230 and Service de Neurologie CHU PURPAN, Toulouse, France
}

SUMMARY Regional cerebral blood flow was investigated using single photon emission computed tomography and xenon-133 intravenous injection in six patients with dementia of the Alzheimer type (DAT) with atypical focal clinical presentation, and in 20 age-matched healthy volunteers. The patients had a progressive and preponderant cognitive deficit and a focal hypoperfusion that correlated with the neuropsychological findings, whereas the average flow did not significantly differ from that of controls. The assessment of concordant haemodynamic and neuropsychological focal abnormalities could be useful in the diagnosis of atypical cases of DAT.

\begin{abstract}
Alzheimer's disease (AD) and dementia of the Alzheimer type (DAT) have long been considered as characterised by a progressive, diffuse and rather homogeneous impairment of cognitive functions. However, isolated or prominent cognitive dysfunction, especially language alterations, have been described in the disease ${ }^{1-3}$ or related to a selective cerebral degeneration. ${ }^{4}$ Histopathological changes especially in the temporoparietal regions have been reported too. ${ }^{5}$ Measurements of local cerebral glucose metabolism by positron emission tomography (PET) or isopropylamphetamine distribution by single photon emission computed tomography (SPECT) have pointed to a bilateral temporoparietal metabolic decrease in Alzheimer's disease. ${ }^{6-9} \mathrm{Re}-$ cently, Friedland et $a l^{10}$ and Haxby et al ${ }^{11}$ emphasised hemispheric asymmetries in demented patients. We studied six patients with DAT and focal oligaemia. In this paper, we compare their haemodynamic status with that obtained from a control group and report the relationships between the regional cerebral blood flow (rCBF) of the patients and their performances on specific cognitive tests.
\end{abstract} Address for reprint requests: P Celsis, LHEC-INSERM U 230,
Service de Neurologie, CHU PURPAN F31059 Toulouse Cedex,
France

Received 25 November 1986 and in revised form 18 March 1987. Accepted 26 March 1987

\section{Material and methods}

\section{Patients}

Out of a series of 36 patients with DAT who underwent a rCBF evaluation by SPECT, we studied six right-handed subjects aged 57 to 75 years (mean age $66 \pm 8 \cdot 1$ ). When referred for the first time to the Department of Neurology, three of them exhibited an elective cognitive deficit, the other three a more diffuse alteration with, however, a disproportionate impairment of one of the cortical functions. Along with the duration of symptoms, that ranged from 1 to 7 years, successive medical evaluations included physical and neurological examinations, neuropsychological testing, laboratory tests, EEGs and CT scans. None of the patients had a family history of DAT. Subjects were free from any motor or sensory deficit. None had a history of cerebrovascular disease (Hachinski ischaemic score ${ }^{12}$ of three or less) and in the two cases where it was performed, the digital angiography was normal. The cerebrospinal fluid (CSF) was studied in three patients and the results were within normal limits. In all cases, folic acid deficiency, hypothyroidism, tertiary neurosyphilis and pernicious anaemia were excluded. EEGs were normal or without obvious focal abnormality. CT scans were normal or showed mild, diffuse cerebral atrophy, sometimes predominating in one of the hemispheres. In each case, neuropsychological evaluation demonstrated a progressive deterioration of intellectual and mnesic abilities in addition to the selective or prominent cognitive deficit. At an early stage of the disease, the symptoms met the criteria for the clinical diagnosis of possible Alzheimer's disease, as given in the report of the NINCDS-ADRDA Work Group on the diagnosis of Alzheimer's disease. ${ }^{13}$ At the time of the flow study, the patients met the criteria of the Work Group for the diagnosis of probable Alzheimer's disease and all six 
patients exhibited symptoms that met the diagnostic criteria for Primary Degenerative Dementia given in the Diagnostic and Statistical Manual of Mental Disorders. ${ }^{14}$

Before the CBF study, informed consent was obtained from the patients or their relatives. Three of them (cases 1, 2 and 6) were retested 8 to 12 months later.

\section{Controls}

We measured cerebral blood flow at rest in 20 age-matched controls (mean age $65 \pm 5 \cdot 2$ years). They underwent clinical and neuropsychological evaluations in order to exclude cerebrovascular disease and cognitive impairment. Ten controls were retested 1 year later. Written informed consent was obtained from the normal volunteers.

\section{$C B F$ measurement}

Regional cerebral blood flow was assessed using a single photon emission tomograph (Tomomatic 64, Medimatic, Copenhagen) and intravenous injection of xenon 133 (2220 MBeq, $60 \mathrm{mCi}$ ). Data were collected from three transverse slices simultaneously, each of $2 \mathrm{~cm}$ thickness, parallel and centred at 1,5 and $9 \mathrm{~cm}$ above the canthomeatal plane respectively. The in-plane resolution was $1.7 \mathrm{~cm}$. During the 4 minute data collection, patients were kept at rest, eyes closed, and pCO2 was continuously recorded using a cutaneous electrode and a Kontron 634 pCO2 monitor. The accuracy of transcutaneous pCO2 recordings had been assessed previously. The values obtained in seven patients both by transcutaneous measurement and from arterial blood samples were compared. Mean value from arterial blood samples was $30.4 \pm 5.3 \mathrm{~mm} \mathrm{Hg}$ (range 22.8-35.9) and mean value from transcutaneous technique was $31 \pm 6 \cdot 2$ (range 22-38). The correlation coefficient was equal to $\overrightarrow{0.979}$,

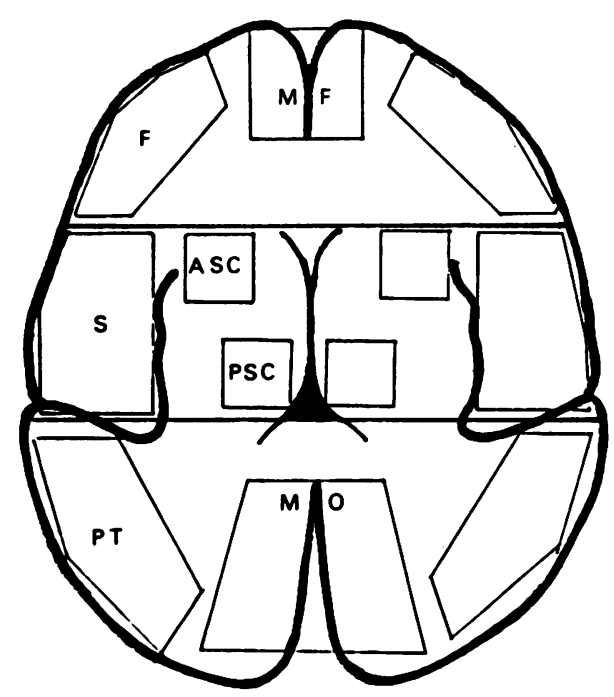

Fig 1 Regions of interest in slice $2(5 \mathrm{~cm}$ above canthomeatal plane). $F=$ frontal; $S=$ sylvian; $P T=$ parietotemporal $; M F=$ middle-frontal; $M O=$ middle-occipital $; A S C=$ anterior sub-cortical; $P S C=$ posterior sub-cortical. thus showing the accuracy of the transcutaneous method when correctly applied (that is, when the electrode is heated up to $44-45^{\circ} \mathrm{C}$ ). A small blood sample was withdrawn for haematocrit determination. CBF was calculated using a method described previously. ${ }^{15}$ Hemispheric flow was determined in slices 2 and 3 . From slice 2, a mean value was derived for the regions of interest (ROI) shown in fig 1 , namely the right and left frontal (F), Sylvian (S) and parietotemporal (PT) cortical regions, the middle frontal (MF) and middle occipital (MO) cortical regions, and the right and left anterior and posterior subcortical regions (ASC and PSC respectively). The ROIs were determined using a semiautomatic method, which first consisted in delimiting the outer contour of the brain by thresholding. Then, the length of the saggital axis (that is, the distance between the frontal and occipital poles), expressed in pixels, was automatically calculated. Two horizontal lines were drawn on the screen: the first at a distance from the most anterior point of the frontal pole equal to $25 \%$ of the saggital length; the second at a distance equal to $60 \%$ of the saggital length. The first line corresponded to the limit between the frontal $(F)$ and Sylvian (S) regions and gave the anterior limit of the ASC region. The second line corresponded to the limit between the Sylvian (S) and parietotemporal (PT) regions and gave the posterior limit of the PSC region. Then, according to this scheme, the ROIs were drawn using predefined templates. Asymmetries, expressed as the percent difference between hemispheres or homologous ROIs were calculated according to the formula:

$$
\operatorname{dif} \%=200 \times \mid \text { Left }- \text { Right }|/| \text { Left }+ \text { Right } \mid
$$

\section{Neuropsychological testing}

Extensive neuropsychological tests were performed in order to appreciate which of the cognitive functions were impaired and to what extent. Owing to the existence of a preponderant mental alteration, the evaluation was adapted to each patient by varying some of the subtests.

Cortical functions For the language evaluation, spontaneous speech, repetition, naming, auditory comprehension, oral reading, reading comprehension and writing were tested by the Protocole MT-85 d'Examen Linguistique de l'Aphasie-version alpha. ${ }^{16}$ Gnosic activities, involving both body image and perceptive as well as associative visual gnosias, were tested by the Protocole Montreal-Toulouse d'évaluation des gnosies visuelles (PEGV). ${ }^{17}$ Constructive practic abilities were evaluated using spontaneous drawing, Rey-Osterrieth complex figure (ROCF) test, ${ }^{18}$ Bendergestalt test ${ }^{19}$ and WAIS block design subtest. ${ }^{20}$ Ideational and ideomotor praxias were tested by imitation of gesture made by the examiner and by ability to perform complex actions.

Mnesic capacities This investigation was based on interviewing the patient, who was asked to describe the main stages of his life or to recall historical and social events, and on the performance on specific tests: Weschler's Memory Scale, ${ }^{21}$ Benton Visual Retention Test, ${ }^{22}$ memory drawing of the Rey-Osterrieth complex figure (ROCF) ${ }^{18}$ and " 144 " Memory Battery Scale. ${ }^{23}$

Intellectual and operative abilities Oral and written arithmetic calculation was tested as well as logical-deductive 
Table 1 Computed tomographic findings, cognitive impairment, pCO2 and regional cerebral blood flow values in six patients with dementiz of the Alzheimer type

\begin{tabular}{|c|c|c|c|c|c|c|c|c|c|}
\hline \multirow[b]{2}{*}{ Case } & \multirow{2}{*}{$\begin{array}{l}\text { Age } \\
(y r)\end{array}$} & \multirow{2}{*}{$\begin{array}{l}\text { Duration } \\
\text { of } \\
\text { symptoms } \\
(y r)\end{array}$} & \multirow[b]{2}{*}{$C T$} & \multirow[b]{2}{*}{ Prominent deficit } & \multirow[b]{2}{*}{$p C O 2$} & \multicolumn{4}{|l|}{ Focal hypoperfusion } \\
\hline & & & & & & $R O I$ & $C B F$ & $n l / 100 \mathrm{~g}$ & \\
\hline \multirow{3}{*}{$\begin{array}{l}1 \\
2\end{array}$} & \multirow{3}{*}{$\begin{array}{l}59 \\
57\end{array}$} & \multirow{3}{*}{$\begin{array}{l}7 \\
3\end{array}$} & \multirow{3}{*}{$\begin{array}{l}\text { Left cortical atrophy } \\
\text { Left cortical atrophy }\end{array}$} & \multirow{3}{*}{$\begin{array}{l}\text { Global aphasia } \\
\text { Anterior aphasia, right } \\
\text { hemivisual neglect }\end{array}$} & \multirow[b]{2}{*}{41} & \multirow[b]{2}{*}{ Left frontal subcort. } & \multirow{2}{*}{$\begin{array}{l}\text { Left } \\
32\end{array}$} & \multirow{2}{*}{$\begin{array}{l}\text { Right } \\
37\end{array}$} & D \\
\hline & & & & & & & & & 15 \\
\hline & & & & & 40 & Left frontal & 45 & 63 & 33 \\
\hline 3 & 60 & 5 & Mild diffuse atrophy & Aphasia & 38 & Left parieto-temporal & 40 & 48 & 18 \\
\hline 4 & 73 & 6 & Mild diffuse atrophy & Aphasia & 38 & Left frontal sylvian & 46 & 54 & 16 \\
\hline 5 & 72 & 1 & Normal & $\begin{array}{l}\text { Constr. apraxia, left } \\
\text { ideomotor aprax. }+ \\
\text { hemivis. neglect. Left }\end{array}$ & & & & & \\
\hline \multirow{3}{*}{6} & \multirow{3}{*}{75} & \multirow{3}{*}{3} & \multirow{3}{*}{ Mild diffuse atrophy } & ear relat. extinction & 33 & Right sylvian & 56 & 50 & 11 \\
\hline & & & & Left hemivisual, left & & & & & \\
\hline & & & & hemimotor neglects & 39 & Right parieto-temporal & 34 & 29 & 1 \\
\hline
\end{tabular}

ROI, region of interest; CBF, cerebral blood flow; Dif (\%), $200 \times \mid$ Left - Right $\mid /$ Left + Right.

reasoning (Raven's Progressive Matrices ${ }^{24}$ and block-forms seriation and classification). The Mini Mental State evaluation (MMS) ${ }^{25}$ was also used as rapid screening test.

\section{Results}

The main results of the neuropsychological testing and SPECT study of cerebral perfusion are summarised in table 1 .

\section{Global CBF findings}

Controls Mean flow in the control group was equal to $50.6 \pm 9.8 \mathrm{ml} / 100 \mathrm{~g} / \mathrm{min}$. Hemispheric flow was 50 \pm 9.5 and $51.1 \pm 10.5$ in the left and right hemisphere respectively. The average percent difference between homologous ROIs never exceeded 6.5 (table 2). The average percent difference between hemispheres was equal to $3 \cdot 1 \pm 2 \cdot 4$, the individual difference never exceeding $7 \%$. In the group of 10 retested controls, mean flow was equal to $52 \cdot 3 \pm 9 \cdot 2$ $\mathrm{ml} / 100 \mathrm{~g} / \mathrm{min}$ at the first measurement and to $54 \cdot 6 \pm$ 8.3 at the second assessment, the difference being not significant. Furthermore, there was no correlation between the hemispheric asymmetries, expressed in percent difference, that were observed at the first and

Table 2 Side to side variations in controls

\begin{tabular}{ll}
\hline$R O I$ & Mean DIF $(\%) \pm S D$ \\
\hline F & $5 \cdot 5 \pm 4 \cdot 6$ \\
PT & $4 \cdot 6 \pm 3 \cdot 5$ \\
ASC & $6 \cdot 1 \pm 3 \cdot 7$ \\
PSC & $6 \cdot 4 \pm 3 \cdot 4$ \\
Hemisphere & $4 \cdot 8 \pm 3 \cdot 8$ \\
\hline
\end{tabular}

ROI, Region of interest; DIF (\%), $200 \times \mid$ Left - Right $/$ Left + Right. second CBF evaluation, neither for the hemispheres nor for any of the ROIs.

Patients All patients exhibited a focal hypoperfusion in one of the hemispheres. Global mean flow was equal to $47 \cdot 7 \pm 8 \cdot 5 \mathrm{ml} / 100 \mathrm{~g} / \mathrm{min}$ and did not significantly differ from the average flow observed in controls. In the hemispheres with focal hypoperfusion, flow was equal to $46.3 \pm 8.2$ and, in the hemispheres without focal hypoperfusion, to $50 \cdot 2 \pm$ $8.9 \mathrm{ml} / 100 \mathrm{~g} / \mathrm{min}$, a value very close to the mean value observed in the control group. The average percent difference between hemispheres equalled $8 \pm 4 \cdot 2$ and significantly differed from the value obtained in controls $(\mathrm{p}<0.01)$. All three patients who were retested 1 year later still exhibited focal hypoperfusion, the? localisation and extent of which were quite similar to those observed at the first examination.

\section{CASE REPORTS}

Case 1

A 59 year old woman began in 1978 to have an elective difficulty in expressing herself. In 1979, when she was referred to the department for the first time, she presented with expressive aphasia with nonfluent speech, word-finding difficulties in visual naming and dysorthographia. Auditory comprehension, repetition and reading aloud were preserved. At this time, practic and gnostic functions were preserved. Patient's score on ROCF copying test was 36 . Imitation of gesture was correct. Right/left orientation was normal and there was no finger agnosia. Objects, familiar faces and places were identified correctly. Spatial and temporal orientations were normal and arithmetic calculation was preserved. Yet, memory was already impaired as revealed by the memory drawing of the ROCF ( 5 points over 36 ). Then, the

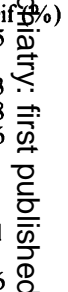




language disturbance gradually progressed and, in 1985 , the patient was unable to communicate since the deficit resembled a global aphasia. Speech output exclusively consisted of the stereotyped word "oui". Writing was limited to copying by graphic imitation and reading comprehension was nil. Although the severity of language disturbance made it difficult to administer some standard tests, we were able to detect a certain degree of deterioration in practic capacities and intellectual abilities. The visuo-constructional function became altered (30 on ROCF copying test and 9 on WAIS block design subtest). An ideomotor apraxia appeared as well as problems in right/left orientation and finger gnosia. Also, the patient failed written calculation. Mnesic capacities were difficult to appreciate but, according to the family, they did not seem to be severely impaired. A mild intellectual deficit was noted and the patient was unable to perform Raven's progressive matrices. The patient continued to perform housekeeping activities although she worked "like an automaton", her husband reported. She was fully oriented and never became lost. Thus, at this stage, the patient exhibited a global mental impairment, yet with preponderant language dysfunction. Physical and neurological examinations were unremarkable. Digital subtraction angiography failed to demonstrate any abnormality on the carotid, vertebral, basilar and great intracranial arteries. The CT scan showed cortical atrophy, more pronounced on the left fronto-temporal region (fig 2a). In 1985, the flow study, (fig $2 \mathrm{~b}$ and table 1 ), revealed a focal area of hypoperfusion in the left hemisphere, corresponding to the frontal and anterior subcortical regions. Flow in the Sylvian and parietotemporal areas was also slightly decreased on the left side. Mean hemispheric values in slice 2 were 38 vs 42 $\mathrm{ml} / 100 \mathrm{~g} / \mathrm{min}$ on left and right side respectively, and 37 vs $39 \mathrm{ml} / 100 \mathrm{~g} / \mathrm{min}$ in slice 3, showing a moderate, global hypoperfusion in this 59 year old patient.

\section{Case 2}

In 1985, a 57 year old man was seen in neurological consultation for the evaluation of marked apathy, unconcern, troubles of elocution and slowing of thinking and memory. Difficulties were first noted 3 years before consultation. The patient was cooperative and aware of his difficulties. The MMS score was equal to 20: orientation $8 / 10$, registration $3 / 3$, attention and calculation $0 / 5$, recall $2 / 3$, language $7 / 9$. He presented with non-fluent speech: the language evaluation showed a poor output, short phrase length, a mild dysarthria and omissions of the small "grammatical" words of the language (articles, pronouns ...). Auditory and reading comprehension was mildly impaired for complex sentences only. Written output was strongly paraphasic, tending to jargonagraphia. The visuoconstructive activities were mildly impaired and showed signs of right hemispatial neglect (omissions and errors in the copy of Rey's figure in the right side only, with a score equal to 28). Calculation and memory were impaired, as shown by MMS evaluation (see above) and Benton VRT (3/10). However, the outstanding neuropsychological deficits called attention to a focal left dysfunction, and more especially to the anterior region since the patient presented with non-fluent aphasia. Yet, the neurological examination, EEG and CSF were strictly normal and a CT scan showed a mild cortical atrophy, more pronounced in the left hemisphere (fig $2 \mathrm{c}$ ). The flow study supported the neuropsychological examination. On the CBF map corresponding to slice 2 (fig 2d), a cortical hypoperfusion was clearly seen in the left frontal region. The local percent difference reached $33 \%$, compared with the opposite ROI (table 1). Low flow was also found in the left anterior subcortical area (52 vs $59 \mathrm{ml} / 100 \mathrm{~g} / \mathrm{min})$. In the other ROIs, flow was slightly depressed by about $6 \%$ on the left side but the mean left and right hemispheric values, 58 and $64 \mathrm{ml} / 100 \mathrm{~g} / \mathrm{min}$ respectively, showed that the brain, as a whole, was correctly perfused.

\section{Case 3}

In 1980, a 60 year old woman first experienced difficulty in expressing herself and in understanding. She was aware of her troubles and depressed. Two years after onset, she was admitted to the department of neurology for a neuropsychological evaluation that showed a global impairment: word-finding difficulties, impoverishment in grammatical competence, mild dysorthographia, constructional apraxia, mild ideomotor apraxia, body image alteration and memory impairment (69 on Wechsler memory scale, 10 over 15 on Benton VRT given in form F). Over the next 3 years, her language gradually worsened, with non-fluent speech, verbal paraphasias and impaired auditory comprehension while the extra-linguistic deficits remained stable. Four successive CT scans, between 1981 and 1984, only showed mild cortical atrophy without focal changes. The cerebrospinal fluid was normal. In 1985, the EEG showed some delta waves in the left temporal lobe. Intravenous angiography showed no abnormality of the carotid, vertebral and basilar arteries. At this stage, the MMS score was found equal to 22 : orientation $8 / 10$, registration $2 / 3$, attention and calculation $3 / 5$, recall $2 / 3$, and language $7 / 9$. In contrast to the rather unremarkable results of the physical and laboratory tests mentioned above, the tomographic data showed a $17 \%$ decrease in CBF in the left parietotemporal region, compared with the contralateral ROI (table 1). Left frontal flow was also slightly diminished 


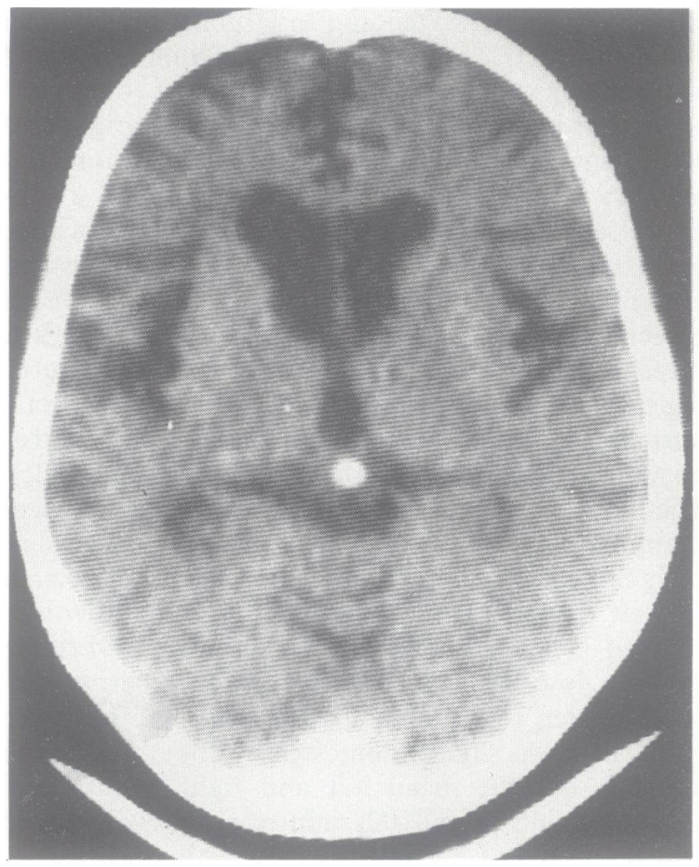

2(a)

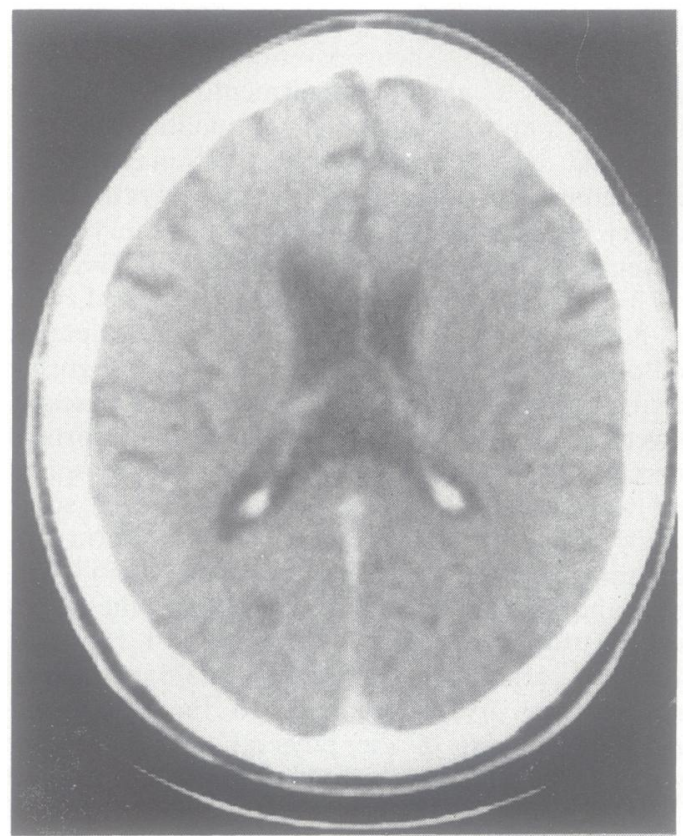

2(c)
Celsis, Agniel, Puel, Rascol, Marc-Vergnes

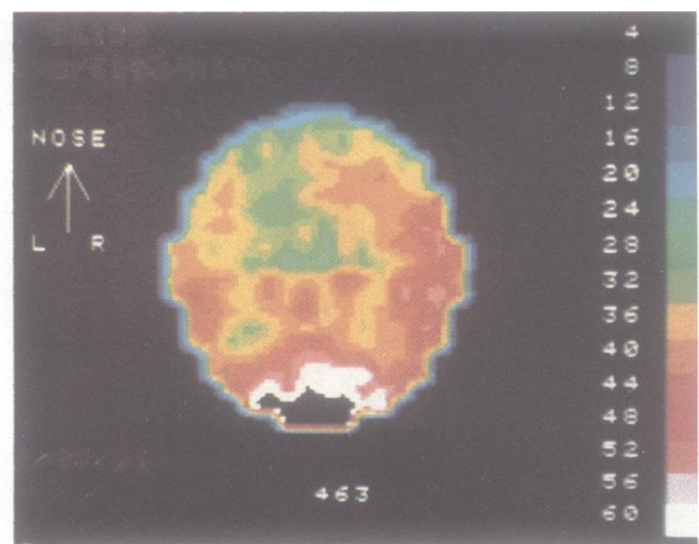

2(b)

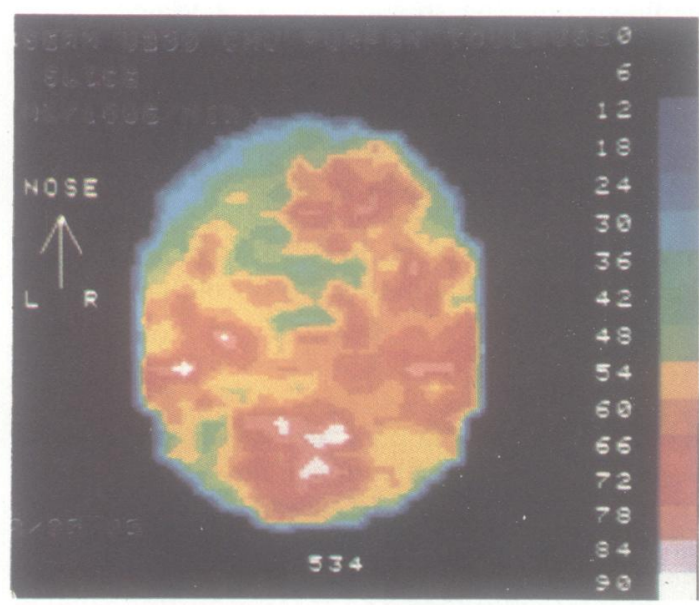

2(d) 
Focal hypoperfusion in dementia of Alzheimer type

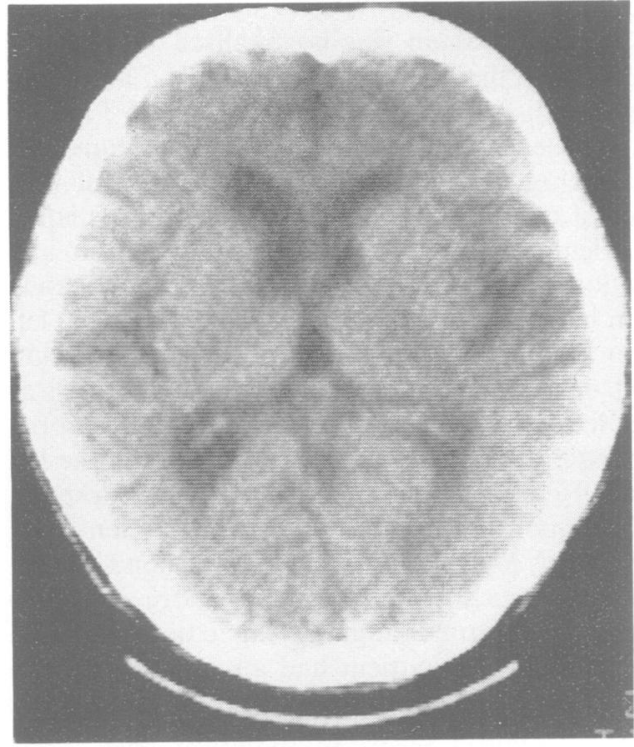

2(e)

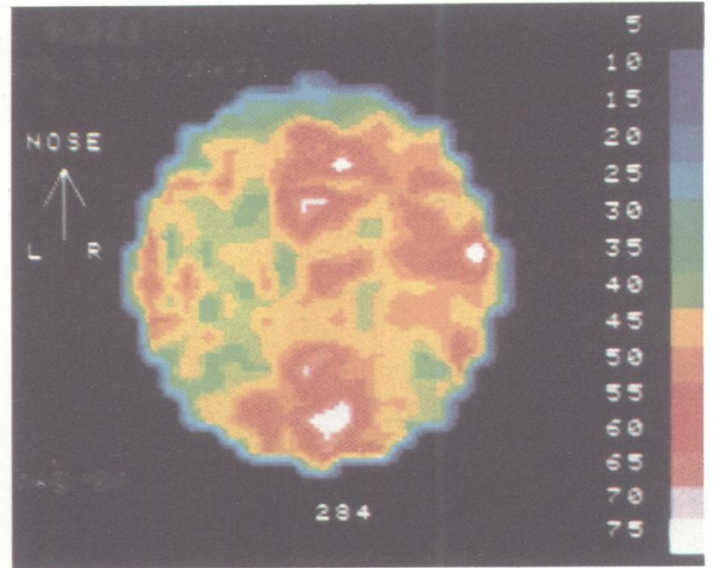

$2(f)$

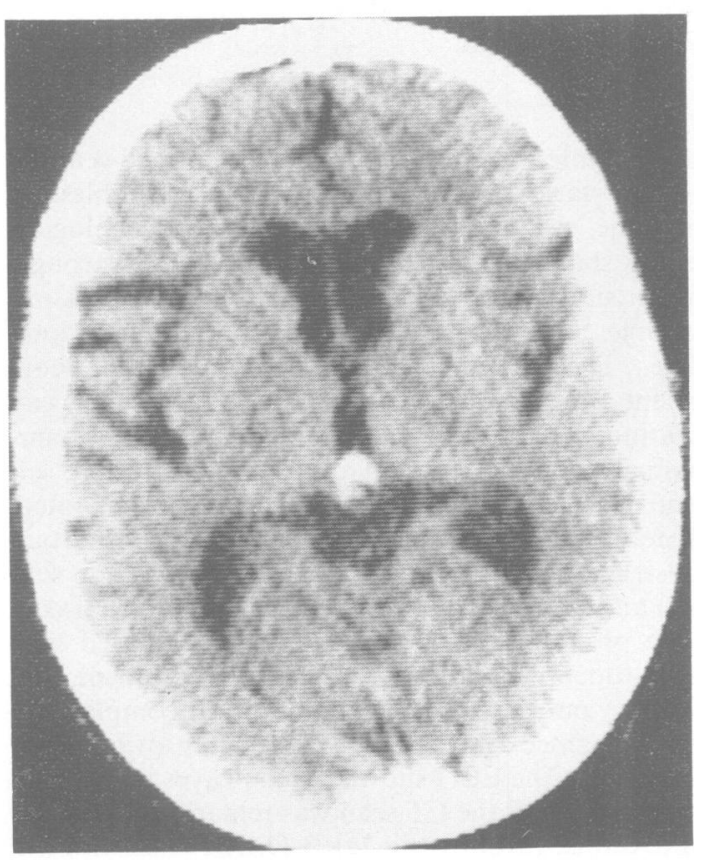

$2(g)$

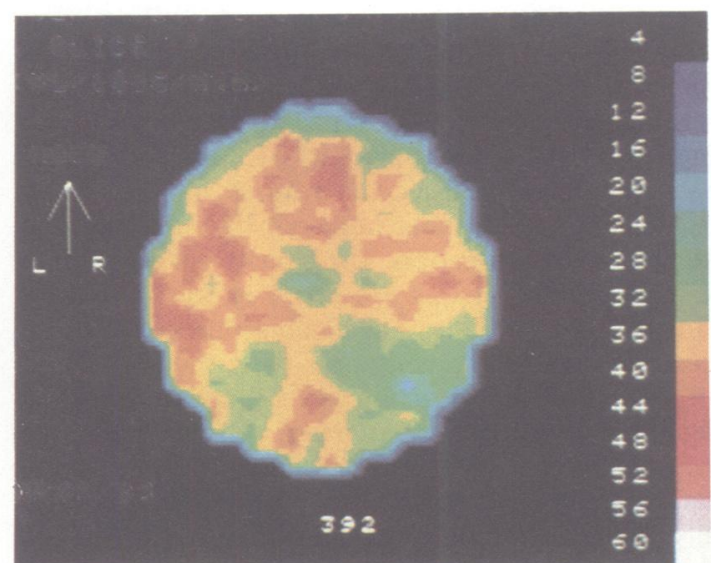

2(h)

Fig $2 C T$ scans $(a, c, e, g)$ and regional cerebral blood flow $(\mathrm{ml} / 100 \mathrm{~g} / \mathrm{min})(b, d, f, h)$ in patients $1,2,4$ and 6 respectively. 
$(-8 \%)$. In slice $2, \mathrm{CBF}$ was equal to 48 and 52 $\mathrm{ml} / 100 \mathrm{~g} / \mathrm{min}$ in left and right hemisphere respectively.

\section{Case 4}

In 1978, a 73 year old man noted the progressive onset of speech disability. One year later, at the first examination, we found word-finding difficulties, semantic and phonemic paraphasias. Practic abilities were normal (35 on ROCF copying test). No gnostic disorder was found at the PEGV. Memory functions and intellectual abilities were slightly impaired (6/10 on Benton VRT, 17/36 on the memory drawing of ROCF). The patient was cooperative and customary activities were preserved. Neurological and EEG findings were normal. During the next years, repeated examinations showed a gradual worsening. Oral reading and reading comprehension became impaired and the deterioration progressively resembled a transcortical sensory aphasia, with fluent but often incoherent speech and numerous paraphasias. Verbal comprehension of complex sentences was impaired. Repetition was normal. Oral activities were relatively more preserved than writing and reading comprehension. Gnosic and operative abilities were preserved. Practic activities, both ideomotor and constructive, were normal but slow. Six years after onset, the auditory comprehension was severely impaired. The patient required several repetitions before comprehending the questions and the responses were delayed. Reading comprehension and writing were deeply affected. Difficulty in arithmetic calculation were noted. Perceptive and associative visual gnosias were strictly normal. The patient performed percentile 50 on PM38 Raven's test. Although difficult to assess because of language alterations, mnesic capacities did not appear more impaired than they were at the previous examination. The patient was oriented to date, place and persons. He was frustrated about his poor language abilities but he continued to perform social and household activities. Thus, in this patient, language was the most impaired function from the beginning and worsened most all through the progression of the disease. EEG showed some bilateral theta waves and two successive CT scans only showed a mild, diffuse cerebral atrophy (fig 2e). This was not the case of the CBF map, slice 2, that showed a pronounced asymmetry (fig $2 \mathrm{f}$ ). Flows equalled 47 and $53 \mathrm{ml} / 100 \mathrm{~g} / \mathrm{min}$ in left and right hemisphere respectively. The hypoperfusion was preponderant in the left frontal and Sylvian cortices (table 1) but also involved the subjacent white matter and basal ganglia. In slices 1 and 3, the flow was also diminished in the left hemisphere (about $10 \%$ ) but the overall perfusion level was good since mean flow in the three slices averaged $50 \mathrm{ml} / 100 \mathrm{~g} / \mathrm{min}$.

\section{Case 5}

A 72 year old woman was hospitalised in 1985 for word-finding difficulties, poor memory and mild temporospatial disorientation of approximately 3 month duration. She was aware of her troubles and anxious. Neuropsychological testing evidenced a deficit in a number of cognitive abilities. MMS score was equal to 23: orientation $6 / 10$, registration $3 / 3$, attention and calculation $5 / 5$, recall $0 / 3$, and language 9/9. However, an ideomotor apraxia predominating at the left superior limb, a constructional apraxia due to an important deficit in visuospatial perception as well as signs of left visual hemineglect (score on ROCF copying test equal to 28 with most of the errors in the left side), a left-ear relative extinction on dichotic test and a spatiotemporal disorientation that the patient tried to correct by logical and deductive reasoning, suggested that cortical dysfunction was more severe on the right side. Normal language capacities supported this hypothesis. The patient had also some difficulty in recognising ward personnel and exhibited euphoric behaviour. Neurological examination and cerebrospinal fluid were normal. An EEG showed right temporal and parietal slowing. CT scan was unremarkable. The 3-D flow study demonstrated an $\vec{\circ}$ elective, moderate hypoperfusion of the right Sylviaro $N$ region (table 1). In contrast, compared with the lefe 응 side, flow was about $5 \%$ higher in the other righ ROIs. On the average, perfusion was identical fo both hemispheres and equalled $51 \mathrm{ml} / 100 \mathrm{~g} / \mathrm{min}$ im slice 2 , a value that could be considered normal in 72 year old patient.

\section{Case 6}

In 1982, three years before admission, this 75 year old woman started to complain of memory troubles. At the time she was hospitalised, neuropsychological testing showed deterioration. Memory was strongly impaired: a verbal learning test of 10 words was impossible. Temporospatial disorientation was complete. The patient achieved 16 on MMS score (orientation $1 / 10$, registration $3 / 3$, attention and calculation $5 / 5$, recall $0 / 3$, language $7 / 9$ ). But, surprisingly, among signs of diffuse deterioration, left hemivisual and hemimotor neglects were noted. Moreover, examination demonstrated an important constructional apraxia ( 0 on WAIS block design subtest) and an upper-limb bilateral ideomotor apraxia, more pronounced on the left side. Compared with other functions, language was preserved, fluent, and difficulty only appeared in elaborating a complex, abstract sentence. The patient was partially aware of her difficulties. The EEG showed theta waves in the right hemisphere and the CT scan was remarkable only for mild, diffuse atrophy (fig 2g). 3-D CBF measurement exhibited a global hypoperfusion (39 and 36 
$\mathrm{ml} / 100 \mathrm{~g} / \mathrm{min}$ in left and right hemisphere respectively), with a reduction in right relative to left parietotemporal region of about $15 \%$ (fig $2 \mathrm{~h}$ ).

\section{Discussion}

Obviously, for lack of histopathological evidence, the diagnosis of Alzheimer's disease can be founded only on the medical history, clinical examination, neuropsychological tests and laboratory studies. From the information thus recorded from our patients, the diagnosis of primary degenerative dementia could be established according to the criteria given in the DSM III ${ }^{14}$ whereas the diagnosis of probable Alzheimer's disease would apply, according to the criteria of McKhann et al. ${ }^{13}$ Therefore, taking into account both the two possible terms, the age of the patients and also to comply with current use in recent literature, we chose the term "dementia of the Alzheimer type" (DAT) to describe our patients.

In our patients, the average flow was not significantly lower than in controls. Besides, flow calculated from the hemispheres with focal hypoperfusion did not differ significantly from the mean value obtained in controls. In the hemispheres without hypoperfusion, the values were within the range of the mean flows observed in controls. Differences between patients and controls only appeared when looking for regional asymmetries. Compared with age-matched controls, bilateral symmetrical reduction of flow has been described in Alzheimer's disease, using the xenon-133 inhalation technique and stationary detectors. ${ }^{2627}$ Tomographic data on CBF in DAT, far from being numerous, essentially consist of those produced by Frackowiak et al, ${ }^{28}$ using $\mathrm{O}^{15}$, who also found bilateral hypoperfusions. Measurement of cerebral glucose rate with PET has also demonstrated bilateral significant diminution in patients with DAT. ${ }^{629}{ }^{30}$ The differences between our results and those reported in the works mentioned above are not due to the technique, as we also, using SPECT, have observed global bilateral decrease in other demented patients, but depend on patient selection. This selection also resulted in the fact that only two cases (Nos 1 and 6) showed a global hypoperfusion, thus achieving a very atypical grouping of demented patients.

All six patients manifested a progressive mental impairment that gradually involved several cognitive functions, so that they could be termed demented. Indeed, for three of them (cases 3, 5 and 6), the diagnosis of dementia had been put forward from the beginning. But they exhibited a disproportionate failure of a specific cognitive capacity: patients 1 to 4 initially showed preponderant language deficits while patients 5 and 6 evidenced a prominent contructional apraxia and left visual and motor hemineglects. Some authors have recently insisted on progressive language alteration in DAT. ${ }^{1-3}$ Kirshner et $a l^{2}$ have suggested a continuous spectrum from isolated aphasia to generalised dementia. Mesulam ${ }^{4}$ suggested that this clinical syndrome could result from a preferential involvement of the left perisylvian region, a special type of progressive degenerative disorder. Recently, Chawluk et $a l^{31}$ reported two cases of slowly progressive aphasia with striking abnormalities of glucose utilisation in the left hemisphere, without any contralateral impairment, as demonstrated by PET. They stressed that their patients did not present with generalised dementia. Our cases have prompted us to a view close of that of Kirshner et al because our patients with prominent language alteration showed a frontal or parietotemporal hypoperfusion and because mild signs of memory failure and reasoning impairment appeared relatively soon in progression of the disease. Since the first CBF examination, in 1985 , one of these patients (case 1), whose language alteration remained by far the most striking-if not the only appreciable - disorder for the 3 or 4 years after onset, has become incontinent.

Concerning the right hemisphere, Crystal et $a^{32}$ reported a patient with biopsy-proved Alzheimer's disease who presented with a right parietal syndrome, 2 years before intellectual impairment appeared. They suggested that the parietal lobes could be initially more affected than other regions. Indeed, two of our patients (cases 5 and 6) evidenced a preponderant dysfunction of the right hemisphere involving the parietal region, but including signs of temporal impairment in case 5. Also considering all six patients, the frontal and perisylvian regions appeared to be initially affected as well. So, our findings might suggest that DAT could begin with different kinds of selective cognitive impairment, related to a left as well as a right hemispheric flow disturbance likely to be shown by haemodynamic studies.

The most striking fact was that all six patients showed a focal cerebral hypoperfusion which was consistent with the neuropsychological findings. This focal hypoperfusion was not a simple hemispheric asymmetry, a finding emphasised by Friedland $e t$ $a l,{ }^{10}$ and which we observed frequently in the remaining patients of our complete series studied by SPECT who presented as mild to moderate Alzheimer's disease. The decrease in flow was indeed wellcircumscribed, sometimes accompanied by a slight global reduction in the ipsilateral hemisphere. Such a haemodynamic pattern resembled those observed in stroke patients. But our patients were not stroke patients. First, they experienced a very slowly progressive deterioration in cognitive ability. Evi- 
dence of the insidious nature of onset was found in the time that elapsed from the beginning of the troubles to the first neurological consultation (several months or years). The regular progression of the disease, together with the absence of focal motor or sensory deficit, also resulted in a Hachinski ischaemic score of 3 or less. Secondly, none of the patients exhibited a focal hypodensity on CT scans. Finally, the digital cerebral angiography we carried out in two patients proved the absence of arterial lesions. In the remaining patients, we found an ischaemic disease so highly improbable that we decided to circumvent the risks of the examination in such weak subjects. Thus, in our series of 36 subjects with DAT, $6(15 \%)$ exhibited a localised flow abnormality consistent with the neuropsychological findings, whereas CT scans only showed mild atrophy, more or less focal, or did not correlate at all. Concerning some common features of Alzheimer's disease and cerebrovascular disease, Benson et al $^{33}$ have warned against the possible misleading diagnosis of degenerative dementia in the presence of angular gyrus syndrome. Among factors distinguishing Alzheimer's disease from the angular gyrus syndrome, they cited the PET study, likely to show highly contrasted metabolic patterns, depending on the disease. Our patients, especially case 3 , suggested that this was not a reliable means for differential diagnosis, as patients with degenerative cognitive disorders (possible or probable DAT) could exhibit focal flow or metabolic abnormalities and not always bilateral parietal and/or frontal disturbances.

Friedland et $a l^{10}$ reported hemispheric asymmetries in glucose utilisation in patients with Alzheimer's disease. They found that the performance on visuospatial tasks was significantly worse in patients with preponderant right-side metabolic impairment than in patients with predominantly left dysfunction. Our results agreed with those of Foster et $^{a l^{34}}$ concerning cortical glucose metabolism in patients with DAT, with the difference that the hypoperfusions we observed seemed more focal than the metabolic abnormalities they reported. The authors found significant relationships between predominant language deficits and left temporoparietal metabolic alterations as well as between disproportionate visuoconstructive dysfunction and right temporoparietal hypometabolism. They noted that patients with a prominent memory failure had no temporoparietal asymmetry in glucose metabolism. We also could not find a patient with a prominent memory deterioration coupled with a focal haemodynamic alteration. Haxby et $a^{11}$ reported significant correlations between two neuropsychological indices of asymmetry of language and visuospatial construction, and regional asymmetry of glucose metabolic rate, whereas Foster et $a l^{34}$ mentioned a close cor- relation between the degree of generalised hypometabolism and the reaction time. Indeed, previous studies with PET have shown a significant relationship between the severity of dementia and the mean cerebral glucose or oxygen utilisation. ${ }^{28} 2935$ Using MRI, Besson et al ${ }^{36}$ found a negative correlation between the constructional subscores and the changes in spin-lattice relaxation time in the parietal regions. The limited number of cases did not allow us to study such quantitative correlations, but it should be remarked that the patient with the greatest memory and reasoning deficits also exhibited the lowest flows (case 6). To be compared with this finding were the results of our study on normals that demonstrated a positive significant relationship between the flow changes during memory activation and a shortterm memory score. ${ }^{37}$

Our results suggested that CBF measurement using SPECT is sensitive and reliable enough to demonstrate asymmetries or focal abnormalities in patients with dementia of the Alzheimer type whereas CT scan usually failed to show such local alterations. Furthermore, these alterations strongly correlated with the neuropsychological tests. As stressed by Khachaturian ${ }^{38}$ "the validation of diagnostic tests remains a crucial problem in all areas of Alzheimer's disease research but especially in the area of neuropsychology". In our work, measuring cerebral blood flow by SPECT thus appeared a good means of consolidating the neuropsychological findings in DAT. In other respects, recent works have emphasised the variability of cognitive profiles ${ }^{39}$ or regional metabolic rates of glucose ${ }^{40}$ in DAT. Reviewing the models currently developed for Alzheimer's disease, Wurtman $^{41}$ said that each model was supported by some observational or experimental evidence, and each seemed to be contradicted by other evidence. Indeed, our work, together with others, ${ }^{11343940}$ points to variability in the clinical expression of the disease, which is the reason why none of the models perfectly matches the observed facts. But it also supports the idea that, combining clinical and neuropsychological examinations with functional mapping of the brain, a subtyping of DAT could be achieved. Thus, for instance, the bilateral posterior decrease in flow or metabolism, a finding now well established, ${ }^{6-9}$ would be ascribed in the subgroup of patients presenting with aphasia, apraxia and agnosia, a subgroup actually different from that of patients with focal abnormality and selective cognitive deficit (such as those presented here), or from that of patients with generalised hypoperfusion or hypometabolism and preponderant memory loss. ${ }^{34}$ To establish such a subtyping would really appear of prime interest as the prognosis could be different and as appropriate treatment could be proposed according to the subgroup. 
To fulfill the latter point supposes that the aetiology and the pathogenetic mechanisms of the disease be elucidated. In this respect too, a subtyping would be rewarding. The factors responsible for the local development of hypoperfusion or hypometabolism have not been determined. The circumscribed decrease in flow could be due to a local amyloid angiopathy which has been observed in Alzheimer's disease. ${ }^{3242}$ Most of the time, a generalised process was observed, involving the whole brain, but recent work has demonstrated unifocal alterations that could account for our focal hypoperfusions. ${ }^{43}$ Besides, in case of amyloid angiopathy, the blood-brain barrier (BBB) might be disrupted, as suggested by Elovaara et al. ${ }^{44}$ This local disruption could in turn lead to neuronal alterations via the intrusion of neurotoxic proteins. In this case, the focal blood flow changes would represent the early stage of the disease. However, Friedland et $a l,{ }^{45}$ using rubidium-82 and PET failed to demonstrate a local permeability of the BBB in patients with generalised DAT. The cortical hypoperfusions we observed might also represent the transynaptic consequence of the degeneration of subcortical cholinergic neurons observed in Alzheimer's disease or senile dementia. ${ }^{4647}$ However, were the subcortical cholinergic neurons the primary focus of the pathological process involved in our cases, the unilateral and rather limited hypoperfusion we observed after years of progression of the disease would appear somewhat disconcerting. Alternatively, the dysfunctional area might reflect a regional, cortical neuronal loss, as suggested by Brun et al..$^{5}$ The neuronal loss could mainly affect the somatostatin neurons, as suggested by Crow $e t a l^{\mathbf{4 8}}$ who found a reduction in somatostatin in the frontal and temporal cortices of patients with DAT, as well as a relationship between the location of neurofibrilliary tangles and the somatostatin-containing cell bodies and who considered these cells as a possible site of primary disturbance. However, whatever the pathogenetic mechanisms involved in DAT, a local biopsy, whenever possible, would still be needed to establish the diagnosis.

Nevertheless, assessing regional cerebral blood flow by SPECT has proved interesting. First, because the technique appeared more sensitive than CT and as sensitive as the much more costly PET technique for the visualisation of focal abnormalities. Secondly, because its results correlated very well with the neuropsychological findings which were thus consolidated. The conjugate haemodynamic and neuropsychological approach might then prove useful in the early diagnosis of DAT. Finally, because the specific pattern of flow it could demonstrate in a subgroup might confirm the validity of the pathogenetic model proposed.
The authors thank Françoise Viala, Christiane Duchein, Gérard Viallard, Thérèse Pujol and $\mathrm{Dr}$ Bernard Doyon for their assistance.

\section{References}

1 Cummings JL, Benson DF, Hill MA, Read S. Aphasia in dementia of the Alzheimer type. Neurology 1985; 35:394-7.

2 Kirshner HS, Webb WG, Kelly MP, Wells CE. Language disturbance. An initial symptom of cortical degenerations and dementia. Arch Neurol 1984;41: 491-6.

3 Wechsler AF. Presenile dementia presenting as aphasia. J Neurol Neurosurg Psychiatry 1977;40:303-5.

4 Mesulam MM. Slowly progressive aphasia without generalized dementia. Ann Neurol 1982;11:592-8

5 Brun A, Englund E. Regional pattern of degeneration in Alzheimer's disease: neuronal loss and histopathological grading. Histopathology 1981;5:549-64.

6 Benson DF, Kuhl DE, Hawkins RA, Phelps ME, Cummings JL, Tsai SY. The fluorodeoxyglucose $18 \mathrm{~F}$ scan in Alzheimer's disease and multi-infarct dementia. Arch Neurol 1983;40:711-4.

7 Friedland RP, Budinger TF, Ganz E, et al. Regional cerebral metabolic alterations in dementia of the Alzheimer type: Positron emission tomography with $\left[{ }^{18}\right.$ F]Fluorodeoxyglucose. J Comput Assist Tomogr 1983;7:590-8.

8 Friedland RP, Brun A, Budinger TF. Pathological and positron emission tomographic correlations in Alzheimer's disease. Lancet 1985;i:228.

9 Gemmel HG, Sharp PF, Evans NTS, Besson JAO, Lyall D, Smith FW. Single photon emission tomography with ${ }^{123}$ I-Isopropylamphetamine in Alzheimer's disease and multi-infarct dementia. Lancet 1984;i: 1348.

10 Friedland RP, Budinger TF, Koss E, Ober BA. Alzheimer's disease: Anterior-posterior and lateral hemispheric alterations in cortical glucose utilization. Neurosci Letters 1985;53:235-40.

11 Haxby JV, Duara R, Grady CL, Cutler NR, Rapoport SI. Relations between neuropsychological and cerebral metabolic asymmetries in early Alzheimer's disease. J Cereb Blood Flow Metabol 1985;5:193-200.

12 Hachinski VC, Iliff LD, Zihlka E, et al. Cerebral blood flow in dementia. Arch Neurol 1975;32:632-7.

13 McKhann G, Drachman D, Folstein M, Katzman R, Price D, Stadlan EM. Clinical diagnosis of Alzheimer's disease: Report of the NINCDS-ADRDA Work Group under the auspices of Department of Health and Human Services Task Force on Alzheimer's disease. Neurology 1984;34:939-44.

14 American Psychiatric Association. Diagnostic and Statistical Manual of Mental Disorders, 3rd Ed. Washington, D.C., APA, 1980.

15 Celsis P, Goldman T, Henriksen L, Lassen NA. A method for calculating regional cerebral blood flow from emission computed tomography of inert gas concentrations. J Comput Assist Tomogr 1981;5:641-5.

16 Dordain M, Nespoulous JL, Bourdeau M, Lecours AR. Capacités verbales d'adultes normaux soumis à un protocole linguistique de l'aphasie. Acta Neurol Belg 
1983;83:5-16.

17 Agniel A, Joanette Y, Doyon B, Duchein C. Protocole d'évaluation des gnosies visuelles. Protocole MontréalToulouse module 2. Montréal. Laboratoire Th Alajouanine. Centre de recherche du Centre Hospitalier Côte-des-Neiges 1987.

18 Rey A. Test de Copie d'une Figure Complexe. Paris. Editions de Centre de Psychologie Appliquée. 1959.

19 Bender L. Test Moteur de Structuration Visuelle de Bender et Adaptation HHR. Paris. Editions de Centre de Psychologie Appliquée. 1968.

20 Wechsler DA. Echelle d'Intelligence de Wechsler pour Adultes. Paris. Editions de Centre de Psychologie Appliquée. 1970.

21 Wechsler DA. Echelle Clinique de Mémoire. Paris. Editions de Centre de Psychologie Appliquée. 1969.

22 Benton AL. Test de Rétention Visuelle. Paris. Editions de Centre de Psychologie Appliquée. 1959.

23 Signoret JL, Whiteley A. A Memory Battery Scale. INS Bulletin 1979;2:26.

24 Raven J. Standard Progressive Matrices PM38-T. Issy les Moulineaux. Editions Scientifiques et Psychologiques. 1976.

25 Folstein MF, Folstein SE, McHugh PR. "Mini-Mental State". A practical method for grading the cognitive state of patients for the clinician. J Psychiatry Res 1975;12:189-98.

26 Yamaguchi F, Meyer JS, Yamamoto M, Sakai F, Shaw T. Noninvasive regional cerebral blood flow measurements in dementia. Arch Neurol 1980;37:410-8.

27 Zemcov A, Barclay L, Vitale V, Blass J. Measurement of cerebral blood flow in the diagnosis of dementias. $J$ Cereb Blood Flow Metabol 1983;3 suppl 1:S512-3.

28 Frackowiak RSJ, Pozzilli, C, Legg NJ, et al. Regional oxygen supply and utilization in dementia. Brain 1981;104:753-78.

29 Cutler NR, Haxby JV, Duara R, et al. Clinical history, brain metabolism, and neuropsychological function in Alzheimer's disease. Ann Neurol 1985;18:298-309.

30 de Leon MJ, Ferris SH, George AE, et al. Computed tomography and positron transaxial tomography evaluations of normal aging and Alzheimer's disease. J Cereb Blood Flow Metabol 1983;3:391-4.

31 Chawluk JB, Mesulam MM, Hurtig H, et al. Slowly progressive aphasia without generalized dementia: studies with positron emission tomography. Ann Neurol 1986;19:68-74.

32 Crystal HA, Horoupian DS, Katzman R, Jotkowitz S. Biopsy-proved Alzheimer disease presenting as a right parietal lobe syndrome. Ann Neurol 1982;12:186-8.

33 Benson DF, Cummings JL, Tsai SY. Angular gyrus syndrome simulating Alzheimer's disease. Arch Neurol 1982;39:616-20.

34 Foster NL, Chase TN, Fedio P, Patronas NJ, Brooks RA, Di Chiro G. Alzheimer's disease: Focal cortical changes shown by positron emission tomography. Neurology 1983;33:961-5.

35 Farkas T, Ferris SH, Wolf AP, et al. 18F-2-deoxy2-fluoro-D-glucose as a tracer in the positron emission tomographic study of senile dementia. Am J Psychiatry 1982;139:352-3.

36 Besson JAO, Corrigan FM, Foreman EI, Eastwood LM, Smith FW, Ashcroft GW. Nuclear magnetic resonance (NMR) II. Imaging in dementia. $\mathrm{Br} J$ Psychiatry 1985;146:31-5.

37 Marc-Vergnes JP, Celsis P, Puel M, Agniel A, Clanet M, Rascol A. SPECT study of blood flow changes in normal and demented patients during memorizing. $J$ Cereb Blood Flow Metabol 1985;5 Suppl 1:S133-4.

38 Khachaturian ZS. Diagnosis of Alzheimer's disease. Arch Neurol 1985;42:1097-104.

39 Neary D, Snowden JS, Bowen DM, et al. Neuropsychological syndromes in presenile dementia due to cerebral atrophy. J Neurol Neurosurg Psychiatry 1986;49:163-74.

40 Metter EJ, Riege WH, Benson DF, Kuhl DE, Phelps ME. Patterns of Regional Cerebral Glucose Metabolism in Alzheimer's Disease Patients. Senile Dementia of the Alzheimer Type. New York: Alan R Liss, Inc. 1985:35-47.

41 Wurtman RJ. Alzheimer's disease. Scientific American 1985;252:48-56.

42 Aikawa H, Suzuki K, Iwasaki Y, Iizuka R. Atypical Alzheimer's disease with spastic paresis and ataxia. Ann Neurol 1985;17:297-300.

43 Cosgrove GR, Leblanc R, Meagher-Villemure K, Ethier R. Cerebral amyloid angiopathy. Neurology 1985;35: 625-31.

44 Elovaara I, Icén A, Palo J, Erkinjuntti T. CSF in Alzheimer's disease. Studies on blood-brain barrier function and intrathecal protein synthesis. $J$ Neurol Sci 1985;70:73-80.

45 Friedland RP, Yano Y, Budinger TF, et al. Quantitative evaluation of blood brain barrier integrity in Alzheimer-type dementia: Positron emission tomographic studies with Rubidium-82. Eur Neurol 1983; 22,Suppl 2:19.

46 Davies P, Maloney AJ. Selective loss of central cholinergic neurones in Alzheimer's disease. Lancet 1976;ii: 1430.

47 Perry EK, Perry RH, Blessed G, Tomlison BE. Necropsy evidence of central cholinergic deficits in senile dementia. Lancet 1977;i: 189.

48 Crow TJ, Cross AJ, Roberts GW, Johnson JA, Corsellis JAN, Peters TJ. Degeneration of cerebral cortical afferents and intrinsic somatostatin neurones in senile dementia of the Alzheimer type with loss of alphaglucoidase activity in temporal cortex. In: Butler RN, Bearn AG, eds. The Aging Process: Therapeutic Implications. New York: Raven Press, 1984:277-91. 